\title{
Impact of Improved Wheat Varieties Adoption on Productivity: Disparity among the Major Administrative Regions of Ethiopia
}

\section{Fitsum Daniel}

Ethiopian Institute of Agricultural Research, Addis Ababa, Ethiopia.

\section{ARTICLE INFO}

Article No.: 112717174

Type: Research

DOI: 10.15580/GJAS.2017.10.112717174

Submitted: $27 / 11 / 2017$

Accepted: 08/12/2017

Published: 30/12/2017

${ }^{*}$ Corresponding Author

Fitsum Daniel

E-mail: fitsum.daniel219

@gmail.com

Phone: 251-0913 384538

Keywords: Impact, Wheat,

Improved Varieties, Ethiopia

\section{ABSTRACT}

This study examines the regional disparity in the impact of adoption of improved wheat varieties on productivity using 1,611 sample farm households in four major administrative regions of Ethiopia. Propensity score matching (PSM) technique was employed since it is an increasingly utilized standard approach for evaluating impacts using observational data. It is found that adoption of improved wheat varieties doesn't have homogenous positive and significant impact on productivity growth in all of the administrative regions considered. Thus, the study recommends that the agricultural research and extension system of the country should further consider the various differences that exist among different regions and areas of the country so as to generate and disseminate suitable improved agricultural technologies and information. 


\section{INTRODUCTION}

Like in many other SSA countries, agriculture in Ethiopia is a basis for the entire socioeconomic structure of the country and has a major influence on all other economic sectors and development processes and hence it plays a crucial role in poverty reduction (Elias et al., 2013; GebreEyesus, 2015). Despite the marginal decline in its share of GDP in recent years, it is still the single largest sector in terms of its contribution to GDP as agricultural GDP constitutes $41 \%$ of total country's GDP (CSA, 2014/15).

As to Gebru 2006 citing CSA 2003, out of the total production of agriculture, about $70 \%$ comes from crop production. According to Abegaz 2011, cereal crops constitute the largest share of farming household's production and consumption activities. Accordingly citing Alemayehu et al., 2009, only five major cereals (barley, maize, sorghum, teff and wheat) account for about $70 \%$ of area cultivated and $65 \%$ of output produced. Fertilizer use is also concentrated on cereals followed by pulses and oilseeds respectively according to Endale 2011 citing CSA 1995/96-2007/08. On the other hand, according to Endale 2011, data from the Ethiopian Seed Enterprise show that improved seeds are mostly used in wheat and maize cultivation with an average of 89 and 42 thousand quintal in the period 1994/95 to 2005/06, respectively. Moreover, Abegaz 2011 citing the Household Income, Consumption and Expenditure Survey of CSA indicated that the five major cereal crops account for $46 \%$ of household's total consumption. Therefore, a closer look at what is happening in cereal production has an important welfare and policy implication in Ethiopia (Abegaz, 2011).

According to Ketema and Kassa 2016 citing Shiferaw et al. 2013, wheat contributes about $20 \%$ of the total dietary calories and proteins worldwide. Ethiopia is the second largest wheat producer in sub-Saharan Africa next to South Africa (Nigussie et al., 2015). Mann and Warner 2017 citing Minot et al. 2015 indicated that there are approximately 4.7 million farmers growing wheat on approximately 1.6 million hectares representing between 15 and $18 \%$ of total crop area and less than $1 \%$ of all wheat production takes place outside the four main regions of Ethiopia according to recent estimates. Wheat is one of the major staple crops in the country in terms of both production and consumption (Kelemu, 2017). According to Kelemu 2017 citing FAO 2014, it is the second most important food in the country behind maize in terms of caloric intake.

The Ethiopian agricultural sector, as to Gebru 2006 citing EEA 2004, is dominated by small-scale farmers cultivating about $96 \%$ of the total area under crop, producing more than $90 \%$ of total agricultural output and $97 \%$ of food crops. With these statistics, one can easily infer to what extent the small-scale farmers are the key element in strengthening the effort towards agricultural growth and consequently to the overall economic growth (Gebre-Selassie \& Bekele).

On the other hand, most smallholder farmers (i.e. $59 \%$ of total cultivated area) reside in the moisture reliable cereal-based highlands among the five agroecological regions of Ethiopia distinguished by agricultural researchers (Taffesse et al., 2012). Accordingly, with farmers using virtually no irrigation, reliable rainfall is an important condition to achieve good agricultural productivity. In relation to this, as to the same source document, the Meher rainfall season is overwhelmingly important as it contributes about $96.9 \%$ of total crop production and $95.5 \%$ of total cereal production in 2007/08.

With respect to all these facts, it is not questionable that accelerated and sustained growth in the country's agriculture in general and in the crop subsector in particular with special emphasis to the smallscale farmers will greatly help to achieve the various goals of the country (Gebru, 2006; MoFED, 2003; Gebre-Selassie \& Bekele).

Moreover, food needs as well as the industrial demand for agricultural products increase due to population growth (Bor and Bayaner, 2009). All these needs, according to them, require an increase in the agricultural production. The growth in agricultural production in sub-Saharan Africa in the past was achieved by expanding the amount of land cultivated (Gebru, 2006). In relation with this, it is well known that in our country there are regions where there are large populations but limited land and vice versa (MoFED, 2003). Accordingly, most of the lands available for settlement are found in the lowlands that lack basic infrastructural facilities and pose serious health hazards. With little suitable land available for expansion of crop cultivation, especially in the highlands, future cereal production growth will need to come from increasing land productivity mainly through the supply, duplication and diffusion of continuously improving technology (Ayele et al. 2006 citing Reardon et al 1996; Taffesse et al. 2012; Elias et al. 2013; Matsumoto and Yamano, 2010).

Cognizant of these as well as the fact that productivity is the major component of growth and a fundamental requisite in many form of planning irrespective of the stage of development and economic and social system as to Gebru 2006 citing Cheema 1978 , the national wheat research program has released and disseminated a number of bread and durum wheat varieties since the 1950s and 1960s as to Ketema and Kassa 2016 citing Tesfaye et al. 2001. According to the same source citing CSA 2015b, a closer look at the proportion of the area covered by improved varieties of different crops showed that wheat took the second rank (7.4\%) next to maize (46.4\%) among cereals. Given the emphasis of increasing crop production through higher fertilizer use, import of chemical fertilizer augmented from 246,722 MT in 1995 to 375,717 MT in 2006 despite 
the removal of fertilizer subsidies since 1997/98 according to Endale 2011 citing MOARD 2007/08. In this regard, according to Ketema and Kassa 2016 citing CSA $2015 \mathrm{~b}$, wheat is the most fertilized crop (82\%) among all crops and pesticide application is also most common on wheat as compared to that on other cereal crops.

Even though crop productivity and production remained low and variable in the 90s for the most part, there have been clear signs of change over the past decade (Abate et al., 2015). According to Kelemu 2017, the average level of wheat productivity for the period of 2000-2014 is about 1.73 ton/ha while the average growth rate in productivity is about $5.93 \%$. During the same period, total wheat production has been increasing at $10.14 \%$ growth rate per annum (Kelemu, 2017).

As to Tsusaka and Otsuka 2013 citing FAO 2011, although the production of staple food has been increasing in sub-Saharan Africa, the rate of increase has not been high enough to outstrip its high population growth rate as a result of which per-capita agricultural production in the region has declined by about $10 \%$ since 1960. These all obviously calls for a further and a better growth in agricultural productivity as well as quality with minimum adverse impact on the environment. Kelemu 2017 citing Shiferaw and Okelo 2011 indicated that of the cereals whose production is soon likely to exceed domestic demand requirements, wheat is the commodity that will most easily find an export market to supply. In view of this prospect, according to him, the need for increasing productivity of wheat is very crucial.

Holistic and appropriate evaluation of the efforts and corresponding results as well as reasons/strengths and weaknesses/ of the past few decades in general and of the past recent years in particular is necessary in order to create a more fertile ground for the fast achievement of the aforementioned goal. In this regard, the role of historical data collected by different agencies like CSA as well as of different socio-economic studies carried out to provide vital policy and related recommendations is indispensable. Studies that assess the contribution of improved technologies like improved crop varieties for the productivity growth of such important and widely cultivated cereals like wheat in Ethiopia in the past recent years are among studies that can be cited in relation to this. However, studies carried out in the country on this issue are not only few but also restricted to piece meal or location specific approach. As a result, the issue has not been satisfactorily and comprehensively assessed at a regional and national level. Thus, the objective of this study is to identify the regional disparity in the impact of adoption of improved wheat varieties on wheat productivity per unit of land cropped among the four major administrative regions of Ethiopia which are also known to be the major wheat producing regions in the country.

\section{ANALYTICAL FRAMEWORK FOR EVALUATION OF ADOPTION OF WHEAT VARIETY IMPACT ON PRODUCTIVITY}

The correct evaluation of the impact of a treatment like adoption of a technology will require identifying the "average treatment effect on the treated" defined as the difference in the outcome variables between the treated objects like farmers and their counterfactual. A counterfactual is defined as "knowledge of what would have happened to those same people if they simultaneously had not received treatment" (Olmos A., 2015 citing Shadish et al., 2002). In this context, as to González et al. 2009, if $Y$ represents the outcome variable and if $D$ is a dummy variable that takes the value of 1 if the individual was treated and 0 otherwise, the "average treatment effect on the treated" will be given by:

$$
\text { (1) } \quad T_{A T T}=E[Y(1) / D=1]-E[Y(0) / D=1]
$$

However, accordingly, given that the counterfactual $(E[Y$ (0) / $D=1]$ ) is not observed, a proper substitute has to be chosen to estimate $T_{A T T}$. Using the mean outcome of non-beneficiaries-which is more likely observed in most of the cases-do not solve the problem given that there is a possibility that the variables that determine the treatment decision also affect the outcome variables. In this case, the outcome of treated and non-treated individuals might differ leading to selection bias (González et al., 2009). To clarify this idea, the mean outcome of untreated individuals has to be added to (1) from which the following expression can be easily derived:

(2) $T_{A T T}=\{E[Y(1) / D=1]-E[Y(0) / D=0]\}-\{E Y Y(0) /$ $D=1]-E[Y(0) / D=0]\}$

Here $E[Y(0) / D=1]-E Y(0) / D=0]$ represents the selection bias which will be equal to zero if treatment was given randomly which can be achieved through the use of experimental approach.

The experimental approach, according to Olmos A. 2015, has two characteristics: (1) it manipulates the independent variable, that is, whether an individual receives (or not) the intervention under scrutiny and (2) individuals are randomly assigned to the independent variable. The first characteristic does not define the experimental approach: most of the so-called quasiexperiments also manipulate the independent variable. What defines the experimental method is the use of random assignment (Olmos A., 2015). However, due to ethical or logistical reasons, random assignment is not possible as to Olmos A. 2015 citing Bonell et al. 2009. Moreover, accordingly, equivalent groups are not achieved despite the use of random assignment which is known as randomization failure. Usual reasons why randomization can fail are associated with missing data which happened in a systematic way and sometimes can go undetected (Olmos A., 2015).

As a consequence of randomization failure, or because of ethical or logistical reasons, in a very large 
number of real-world interventions, experimental approaches are impossible or very difficult to implement. However, if we are still interested in demonstrating the causal link between our intervention and the observed change, our options become limited. Some options include regression discontinuity designs which can strengthen our confidence about causality by selecting individuals to either the control or treatment condition based on a cutoff score. Another alternative is propensity scores matching technique. Propensity scores matching is a statistical technique that has proven useful to evaluate treatment effects when using quasi-experimental or observational data (Olmos A., 2015 citing Austin, 2011 and Rubin, 1983). Some of the benefits associated with this technique, accordingly, are: (a) Creating adequate counterfactuals when random assignment is infeasible or unethical, or when we are interested in assessing treatment effects from survey, census administrative, or other types of data, where we cannot assign individuals to treatment conditions. (b) The development and use of propensity scores reduces the number of covariates needed to control for external variables (thus reducing its dimensionality) and increasing the chances of a match for every individual in the treatment group. (c) The development of a propensity score is associated with the selection model, not with the outcomes model, therefore the adjustments are independent of the outcome. According to Olmos A. 2015 , propensity scores are defined as the conditional probability of assigning a unit to a particular treatment condition (i.e., likelihood of receiving treatment), given a set of observed covariates:

$$
(z=i \mid \mathrm{X})
$$

where $\mathrm{z}=$ treatment, $\mathrm{i}=$ treatment condition, and $\mathrm{X}=$ covariates. In a two-group (treatment, control) experiment with random assignment, the probability of each individual in the sample to be assigned to the treatment condition is: $\quad(z=i \mid X)=0.5$. In a quasiexperiment, the probability $(z=i \mid X)$ is unknown, but it can be estimated from the data using a logistic regression model, where treatment assignment is regressed on the set of observed covariates (the socalled selection model). The propensity score then allows matching of individuals in the control and treatment conditions with the same likelihood of receiving treatment. Thus, a pair of participants (one in the treatment, one in the control group) sharing a similar propensity score are seen as equal, even though they may differ on the specific values of the covariates (Olmos A. 2015 citing Holmes 2014).

\section{DATA}

The data utilized for this study is acquired from farm household survey undertaken during 2015/16 by Ethiopian Institute of Agricultural Research (EIAR) in collaboration with the International Maize and Wheat Improvement Center (CIMMYT). The sampling frame covered seven major wheat growing agro-ecological zones that accounted for over $85 \%$ of the national wheat area and production distributed in the four major administrative regions of Ethiopia- Oromia, Tigray, Amhara as well as South Nations, Nationalities and Peoples (SNNP). A multi-stage stratified sampling procedure was used to select villages from each agroecology, and households from each "kebele"/village. First, agro-ecological zones that account for at least 3\% of the national wheat area each were selected from all the major wheat growing regional states of the country mentioned above. Second, based on proportionate random sampling, up to 21 villages in each agroecology, and 15 to 18 farm households in each village were randomly selected. The data was collected using a pre-tested interview schedule by trained and experienced enumerators who speak the local language and have good knowledge of the farming systems. Moreover, the data collection process was supervised by experienced researchers to ensure the quality of the data.

\section{RESULTS AND DISCUSSIONS}

\section{Descriptive Statistics}

Various variables that were included in the propensity score matching model that describe the major observed characteristics of the sample respondents are presented in table 1 . In Oromia and Tigray regions, the productivity of improved wheat varieties adopters is significantly greater than that of non-adopters. Thus, it tentatively shows that there is significant difference in productivity level in these regions between those households that adopt improved wheat varieties and those that do not adopt improved wheat varieties. Those farmers who had contact with government extension workers are more likely to adopt improved wheat varieties than those that had not in all the four regions considered. Both age of a household head as well as the number of oxen owned by a household influence the probability of adoption of improved wheat varieties in two of the regions-Oromia and SNNP. Moreover, while household head's age affected the probability of adoption in Amhara region, oxen ownership affected it in Tigray region though the type of effect of both variables vary across the regions. While sex of a household head has similar type of effect on the probability of adoption in Tigray and Amhara regions, landholding size has similar type of effect on the probability of adoption in Tigray and Oromia regions. However, the rest five variables has effect on the probability of adoption in only one of the regions considered-family size, credit availability and distance to the nearest main market in Amhara region, literacy of the household head in Oromia region as well as total 
number of traders known who could buy the produced grain in Tigray region.

\section{Propensity Scores Estimation using Probit Model}

The descriptive statistics of the key variables affecting technology adoption has shown a tentative impact of improved wheat varieties adoption on increasing productivity in some of the regions. Nevertheless, a mere comparison of productivity has no causal meaning since improved wheat varieties adoption is endogenous. And it is difficult to attribute the change to adoption of improved wheat varieties since the difference in productivity might be owing to other determinants. To this end, a rigorous impact evaluation method; namely, Propensity Score Matching has to be employed to control for observed characteristics and determine the actual attributable impact of improved wheat varieties adoption on productivity in different wheat producing regions of Ethiopia. Propensity scores for adopters and non-adopters were estimated using a probit model to compare the treatment group with the control group. In this regard, only those variables that significantly affect probability of improved wheat varieties adoption were used in estimating the propensity scores for each region. The test for 'balancing condition' across the treatment and control groups was done and the result as indicated on figure 1 proved that the balancing condition is satisfied for all the four regions considered.

Each observation's propensity scores are calculated using a probit model. For Oromia region, the propensity score for adopters ranges between 0.7009652 and 0.9757828 while it ranges between 0.6412518 and 0.9657442 for non-adopters and the region of common support for the distribution of estimated propensity scores of adopters and nonadopters ranges between 0.70096522 and 0.97578283 . For Tigray region, the propensity score for adopters ranges between 0.4271473 and 0.9881623 while it ranges between 0.2006323 and 0.8827971 for nonadopters and the region of common support for the distribution of estimated propensity scores of adopters and non-adopters ranges between 0.42714733 and 0.98816232 . For Amhara region, the propensity score for adopters ranges between 0.4396551 and 0.947241 while it ranges between 0.4470613 and 0.8923695 for non-adopters and the region of common support for the distribution of estimated propensity scores of adopters and non-adopters ranges between 0.43965508 and 0.94724096 . For SNNP region, the propensity score for adopters ranges between 0.7778119 and 0.9995403 while it ranges between 0.7155614 and 0.9978239 for non-adopters and the region of common support for the distribution of estimated propensity scores of adopters and non-adopters ranges between 0.77781188 and 0.99954027 . When matching techniques are employed, observations whose propensity score lies outside this range were discarded. The visual presentation of the distributions of the propensity scores is plotted in figure 1. The common support condition is satisfied as indicated by the density distributions of the estimated propensity scores for the treatment and control groups as there is substantial overlap in the distribution of the propensity scores of both adopters and non-adopters.

\section{Assessing Matching Quality}

Ensuring good balance between treated and control group is the most important step in using any propensity score method. The before and after matching covariate balancing tests presented on table 2 suggested that the proposed specification of the propensity score is fairly successful in balancing the distribution of covariates between the two groups as indicated by decreasing pseudo $R^{2}$ for all regions except SNNP, decreasing mean standardized bias for all regions and the insignificant $p$-values of the likelihood ratio test for Tigray and SNNP regions.

\section{RESULTS}

Different impact estimators were employed to get estimated treatment effect. Table 3 depicts the average impact of improved wheat varieties adoption on productivity growth for each of the four regions of interest following nearest neighbor matching (NNM), Stratification Matching, Radius (Caliper) Matching and Kernel Matching (KM) techniques. Accordingly, there is at least some evidence to support the hypothesis that improved wheat varieties adoption has a positive and significant impact on productivity growth in only two of the four regions considered, namely Oromia and Tigray. Moreover, improved wheat varieties adoption has a higher impact on productivity growth in Oromia region, ranging from $28-43 \%$, compared to that in Tigray region, ranging from 23-24\%. However, improved wheat varieties adoption doesn't have a positive and significant impact on productivity growth in the rest two regionsAmhara and SNNP. Furthermore, its impact turns out to be negative in case of SNNP region. This can be due to various relevant factors that vastly vary among regions like concentration of well-capacitated agricultural research centers (such as federal agricultural research centers of the Ethiopian Institute of Agricultural Research) and associated faster adoption of newly released relevant improved agricultural technologies and information by near-by farmers. This obviously needs to be well-articulated by further additional studies that use detailed data like the type of improved wheat variety adopted by farmers.

\section{CONCLUSION AND RECOMMENDATION}

This study is undertaken to identify the regional disparity in the impact of adoption of improved wheat varieties on wheat productivity among different major wheat producing administrative regions of Ethiopia. It used propensity score matching technique which is a robust 
impact evaluation technique that identifies the impact which can be attributed to improved wheat varieties adoption. The study also employed and compared various matching algorithms to ensure robustness of the impact estimates. Finally, the study concludes that adoption of improved wheat varieties that were released and disseminated so far doesn't have the desired positive and significant impact on productivity growth in all of the different major wheat producing administrative regions of the country. Moreover, their impact greatly varies among the regions. Therefore, this study recommends that the agricultural research and extension system of the country should be strengthened to further take into account the differences among different regions and areas (like zones, woredas and "kebeles"/villages) in order to generate and scale-up improved wheat varieties as well as other appropriate improved agricultural technologies and information that suits to the specific conditions of all wheat producing farm households of the country. 


\section{Tables and Figures}

Table 1: Descriptive statistics of important variables used in the probit model-Propensity Score Matching

\begin{tabular}{|c|c|c|c|c|c|c|c|c|c|c|c|c|c|c|c|c|c|}
\hline \multirow[t]{2}{*}{ Variables } & \multirow[t]{2}{*}{ Unit } & \multicolumn{4}{|c|}{$\begin{array}{l}\text { Adopters } \\
\text { Mean(se) }\end{array}$} & \multicolumn{4}{|c|}{$\begin{array}{c}\text { Non-adopters } \\
\text { Mean(se) }\end{array}$} & \multicolumn{4}{|c|}{$\begin{array}{c}\text { Aggregate } \\
\text { Mean(se) }\end{array}$} & \multicolumn{4}{|c|}{ t-stat. } \\
\hline & & Oromia & Tigray & Amhara & SNNP & Oromia & Tigray & Amhara & SNNP & Oromia & Tigray & Amhara & SNNP & Oromia & Tigray & Amhara & SNNP \\
\hline Outcome variable & & & & & & & & & & & & & & & & & \\
\hline Productivity & $\#$ & $\begin{array}{l}1877.69 \\
(39.62)\end{array}$ & $\begin{array}{l}1934.90 \\
(163.69)\end{array}$ & $\begin{array}{l}1442.87 \\
(48.57)\end{array}$ & $\begin{array}{c}1546.15 \\
(75.21)\end{array}$ & $\begin{array}{c}1203.89 \\
(74.10)\end{array}$ & $\begin{array}{l}1343.20 \\
(116.64)\end{array}$ & $\begin{array}{l}1382.25 \\
(74.48)\end{array}$ & $\begin{array}{l}2122.42 \\
(279.78)\end{array}$ & $\begin{array}{l}1794.78 \\
(36.71)\end{array}$ & $\begin{array}{l}1815.15 \\
(134.93)\end{array}$ & $\begin{array}{l}1426.68 \\
(40.76)\end{array}$ & $\begin{array}{l}1565.26 \\
(73.60)\end{array}$ & $-6.16^{\star \star \star}$ & $-1.79^{\star *}$ & -0.66 & $1.41^{*}$ \\
\hline $\begin{array}{l}\text { Variables that affect } \\
\text { probability of } \\
\text { adoption }\end{array}$ & & & & & & & & & & & & & & & & & \\
\hline HHAGE & $\#$ & $\begin{array}{l}45.11 \\
(0.46)\end{array}$ & $\begin{array}{l}48.54 \\
(1.38)\end{array}$ & $\begin{array}{l}46.23 \\
(0.67)\end{array}$ & $\begin{array}{l}44.59 \\
(0.85)\end{array}$ & $\begin{array}{l}48.03 \\
(1.46)\end{array}$ & $\begin{array}{l}49.94 \\
(3.24) \\
\end{array}$ & $\begin{array}{l}48.30 \\
(1.12)\end{array}$ & $\begin{array}{l}37.17 \\
(3.37) \\
\end{array}$ & $\begin{array}{l}45.47 \\
(0.45)\end{array}$ & $\begin{array}{l}48.82 \\
(1.27)\end{array}$ & $\begin{array}{l}46.78 \\
(0.57) \\
\end{array}$ & $\begin{array}{l}44.34 \\
(0.83) \\
\end{array}$ & $2.15^{\star \star}$ & 0.44 & $1.61^{*}$ & $-1.61^{*}$ \\
\hline HHSEX (Male=1) & $\begin{array}{c}1=Y e \\
s\end{array}$ & $\begin{array}{c}0.91 \\
(0.011)\end{array}$ & $\begin{array}{c}0.81 \\
(0.049)\end{array}$ & $\begin{array}{c}0.92 \\
(0.014)\end{array}$ & $\begin{array}{c}0.93 \\
(0.019)\end{array}$ & $\begin{array}{c}0.93 \\
(0.025) \\
\end{array}$ & $\begin{array}{c}0.94 \\
(0.059)\end{array}$ & $\begin{array}{c}0.96 \\
(0.018)\end{array}$ & $1(0)$ & $\begin{array}{c}0.91 \\
(0.010)\end{array}$ & $\begin{array}{c}0.83 \\
(0.041)\end{array}$ & $\begin{array}{c}0.93 \\
(0.011) \\
\end{array}$ & $\begin{array}{c}0.93 \\
(0.019)\end{array}$ & 0.82 & $1.33^{*}$ & $1.33^{*}$ & 0.66 \\
\hline FAMILYSIZE & $\#$ & $\begin{array}{c}7.12 \\
(0.087) \\
\end{array}$ & $\begin{array}{c}6.15 \\
(0.25) \\
\end{array}$ & $\begin{array}{c}5.51 \\
(0.081) \\
\end{array}$ & $\begin{array}{c}7.06 \\
(0.16) \\
\end{array}$ & $\begin{array}{c}7.22 \\
(0.22) \\
\end{array}$ & $\begin{array}{c}6.29 \\
(0.46) \\
\end{array}$ & $\begin{array}{l}5.72 \\
(0.14) \\
\end{array}$ & $6(1.18)$ & $\begin{array}{c}7.14 \\
(0.081) \\
\end{array}$ & $\begin{array}{c}6.18 \\
(0.22) \\
\end{array}$ & $\begin{array}{c}5.57 \\
(0.070) \\
\end{array}$ & $\begin{array}{c}7.03 \\
(0.16) \\
\end{array}$ & 0.41 & 0.26 & $1.33^{*}$ & -1.185 \\
\hline $\begin{array}{l}\text { HHEDU } \\
\text { write }=1)\end{array} \quad$ (Read $\quad$ \& & $1=$ yes & $\begin{array}{l}0.695 \\
(0.017)\end{array}$ & $\begin{array}{c}0.58 \\
(0.061)\end{array}$ & $\begin{array}{c}0.50 \\
(0.026)\end{array}$ & $\begin{array}{c}0.79 \\
(0.031)\end{array}$ & $\begin{array}{c}0.602 \\
(0.048)\end{array}$ & $\begin{array}{c}0.47 \\
(0.12)\end{array}$ & $\begin{array}{c}0.45 \\
(0.043)\end{array}$ & $1(0)$ & $\begin{array}{c}0.683 \\
(0.016)\end{array}$ & $\begin{array}{c}0.56 \\
(0.054)\end{array}$ & $\begin{array}{c}0.49 \\
(0.022)\end{array}$ & $\begin{array}{c}0.80 \\
(0.030)\end{array}$ & $-1.90^{\star \star}$ & -0.82 & -1.054 & 1.26 \\
\hline CREDIT & $1=$ yes & $\begin{array}{c}0.034 \\
(0.007) \\
\end{array}$ & $\begin{array}{c}0.36 \\
(0.059) \\
\end{array}$ & $\begin{array}{c}0.10 \\
(0.016) \\
(\end{array}$ & $\begin{array}{c}0.069 \\
(0.019) \\
\end{array}$ & $\begin{array}{c}0.019 \\
(0.014) \\
\end{array}$ & $\begin{array}{c}0.29 \\
(0.11) \\
\end{array}$ & $\begin{array}{c}0.037 \\
(0.016) \\
\end{array}$ & $0(0)$ & $\begin{array}{c}0.032 \\
(0.006) \\
\end{array}$ & $\begin{array}{c}0.35 \\
(0.052) \\
\end{array}$ & $\begin{array}{c}0.084 \\
(0.012) \\
\end{array}$ & $\begin{array}{l}0.066 \\
(0.019 \\
\end{array}$ & -0.79 & -0.49 & $-2.35^{\star \star *}$ & -0.66 \\
\hline LANDHOLDING_SIZE & $\mathrm{Ha}$ & $\begin{array}{c}1.88 \\
(0.054) \\
\end{array}$ & $\begin{array}{c}0.79 \\
(0.052) \\
\end{array}$ & $\begin{array}{c}1.08 \\
(0.037) \\
\end{array}$ & $\begin{array}{c}1.41 \\
(0.077) \\
\end{array}$ & $\begin{array}{c}2.31 \\
(0.196) \\
\end{array}$ & $\begin{array}{c}1.02 \\
(0.19) \\
\end{array}$ & $\begin{array}{c}1.04 \\
(0.053) \\
\end{array}$ & $\begin{array}{l}1.18 \\
(0.36 \\
\end{array}$ & $\begin{array}{c}1.93 \\
(0.053) \\
\end{array}$ & $\begin{array}{c}0.84 \\
(0.057) \\
\end{array}$ & $\begin{array}{c}1.07 \\
(0.031) \\
\end{array}$ & $\begin{array}{c}1.40 \\
(0.075) \\
\end{array}$ & $2.66^{* \star *}$ & $1.67^{*}$ & -0.54 & -0.559 \\
\hline DSTMNMKT & $\mathrm{Km}$ & $\begin{array}{l}10.43 \\
(0.24)\end{array}$ & $\begin{array}{l}8.15 \\
(0.41)\end{array}$ & $\begin{array}{c}8.21 \\
(0.29)\end{array}$ & $\begin{array}{c}6.34 \\
(0.30) \\
\end{array}$ & $\begin{array}{l}10.15 \\
(0.49)\end{array}$ & $\begin{array}{c}7.74 \\
(0.50)\end{array}$ & $\begin{array}{c}7.37 \\
(0.41) \\
\end{array}$ & $\begin{array}{c}5.75 \\
(1.57) \\
\end{array}$ & $\begin{array}{l}10.40 \\
(0.22)\end{array}$ & $\begin{array}{c}8.07 \\
(0.34) \\
\end{array}$ & $\begin{array}{c}7.98 \\
(0.24)\end{array}$ & $\begin{array}{c}6.32 \\
(0.29)\end{array}$ & -0.43 & -0.49 & $-1.54^{*}$ & -0.36 \\
\hline TNOTRAREDS & $\#$ & $\begin{array}{c}4.52 \\
(0.19) \\
\end{array}$ & $\begin{array}{c}1.24 \\
(0.28) \\
\end{array}$ & $\begin{array}{c}4.21 \\
(0.31) \\
\end{array}$ & $\begin{array}{c}5.42 \\
(0.47) \\
\end{array}$ & $\begin{array}{c}4.01 \\
(0.42) \\
\end{array}$ & $\begin{array}{c}2.71 \\
(1.20) \\
\end{array}$ & $\begin{array}{c}4.06 \\
(0.48) \\
\end{array}$ & $\begin{array}{c}3.67 \\
(0.99) \\
\end{array}$ & $\begin{array}{c}4.46 \\
(0.17) \\
\end{array}$ & $\begin{array}{c}1.54 \\
(0.33) \\
\end{array}$ & $\begin{array}{c}4.17 \\
(0.26) \\
\end{array}$ & $\begin{array}{c}5.36 \\
(0.46) \\
\end{array}$ & -0.96 & $1.79^{\star \star}$ & -0.26 & -0.686 \\
\hline EXCONTACT & $1=$ yes & $\begin{array}{c}0.83 \\
(0.014)\end{array}$ & $\begin{array}{c}0.91 \\
(0.035)\end{array}$ & $\begin{array}{c}0.91 \\
(0.015)\end{array}$ & $\begin{array}{c}0.76 \\
(0.032)\end{array}$ & $\begin{array}{c}0.69 \\
(0.046)\end{array}$ & $\begin{array}{c}0.71 \\
(0.11) \\
\end{array}$ & $\begin{array}{c}0.84 \\
(0.032)\end{array}$ & $\begin{array}{c}0.50 \\
(0.22)\end{array}$ & $\begin{array}{c}0.81 \\
(0.014)\end{array}$ & $\begin{array}{c}0.87 \\
(0.037)\end{array}$ & $\begin{array}{c}0.89 \\
(0.014)\end{array}$ & $\begin{array}{c}0.75 \\
(0.032) \\
\end{array}$ & $-3.44^{\star * *}$ & $-2.27^{\star *}$ & $-2.47^{\star \star *}$ & $-1.449^{*}$ \\
\hline
\end{tabular}

${ }^{\star \star *},{ }^{\star \star},{ }^{*}$ indicate significance at 1 percent, 5 percent and 10 percent level respectively.

Source: Own computation, 2017 
Table 2: Propensity Score Matching Quality Test

\begin{tabular}{|c|l|c|c|c|c|c|c|}
\hline Region & Sample & Ps R2 & LR chi2 & p>chi2 & MeanBias & MedBias & $\%$ Var \\
\hline \multirow{2}{*}{ Oromia } & Unmatched & 0.030 & 18.90 & 0.002 & 21.5 & 19.5 & 100 \\
\cline { 2 - 8 } & Matched & 0.004 & 8.12 & 0.150 & 5.6 & 5.5 & 67 \\
\hline \multirow{2}{*}{ Tigray } & Unmatched & 0.119 & 10.03 & 0.074 & 37.0 & 35.0 & 100 \\
\cline { 2 - 8 } & Matched & 0.098 & 18.24 & 0.003 & 27.5 & 22.6 & 67 \\
\hline \multirow{2}{*}{ Amhara } & Unmatched & 0.032 & 18.84 & 0.004 & 18.0 & 16.0 & 33 \\
\cline { 2 - 8 } & Matched & 0.006 & 6.07 & 0.415 & 4.9 & 2.2 & 33 \\
\hline \multirow{2}{*}{ SNNP } & Unmatched & 0.190 & 10.02 & 0.018 & 64.2 & 64.2 & 100 \\
\cline { 2 - 8 } & Matched & 0.224 & 108.08 & 0.000 & 33.5 & 40.9 & 100 \\
\hline
\end{tabular}

${ }^{*}$ if $\mathrm{B}>25 \%, \mathrm{R}$ outside $[0.5 ; 2]$

Table 3: Average Treatment Effects estimation using different propensity score matching estimators

\begin{tabular}{|c|c|c|c|c|c|c|}
\hline \multirow[t]{2}{*}{ Region } & \multirow{2}{*}{$\begin{array}{l}\text { Outcome } \\
\text { Variable }\end{array}$} & \multirow{2}{*}{$\begin{array}{l}\text { Matching } \\
\text { Algorithm }\end{array}$} & \multicolumn{2}{|c|}{$\begin{array}{c}\text { Mean of Outcome } \\
\text { Variable Based on } \\
\text { Matched } \\
\text { Observations }\end{array}$} & \multirow[b]{2}{*}{ ATT } & \multirow[b]{2}{*}{ t-stat. } \\
\hline & & & Adopters & $\begin{array}{c}\text { Non- } \\
\text { adopters }\end{array}$ & & \\
\hline \multirow{4}{*}{ Oromia } & \multirow{4}{*}{ LnProductivity } & Nearest Neighbor Matching & 7.37 & 6.94 & 0.427 & 4.937 \\
\hline & & Stratification Matching & & & 0.366 & 5.675 \\
\hline & & Caliper Matching & 7.35 & 7.07 & 0.282 & 3.463 \\
\hline & & Kernel Matching & 7.37 & 6.99 & 0.379 & 6.177 \\
\hline \multirow{4}{*}{ Tigray } & \multirow{4}{*}{ LnProductivity } & Nearest Neighbor Matching & 7.37 & 7.17 & 0.199 & 1.081 \\
\hline & & Stratification Matching & & & 0.238 & $1.399^{\circ}$ \\
\hline & & Caliper Matching & 7.29 & 7.17 & 0.116 & 0.763 \\
\hline & & Kernel Matching & 7.37 & 7.14 & 0.226 & 1.549 \\
\hline \multirow{4}{*}{ Amhara } & \multirow{4}{*}{ LnProductivity } & Nearest Neighbor Matching & 7.09 & 7.06 & 0.033 & 0.328 \\
\hline & & Stratification Matching & & & 0.071 & 0.989 \\
\hline & & Caliper Matching & 7.03 & 7.03 & 0.002 & 0.022 \\
\hline & & Kernel Matching & 7.09 & 7.03 & 0.056 & 0.847 \\
\hline \multirow{4}{*}{ SNNP } & \multirow{4}{*}{ LnProductivity } & Nearest Neighbor Matching & 7.14 & 7.57 & -0.429 & -1.741 \\
\hline & & Stratification Matching & & & -0.417 & -2.092 \\
\hline & & Caliper Matching & 6.97 & 7.69 & -0.713 & -1.961 \\
\hline & & Kernel Matching & 7.14 & 7.55 & -0.412 & -3.186 \\
\hline
\end{tabular}

*** significant at $1 \%$ \& bootstrapped standard errors are based on 100 replications.

Source: Own computation, 2017

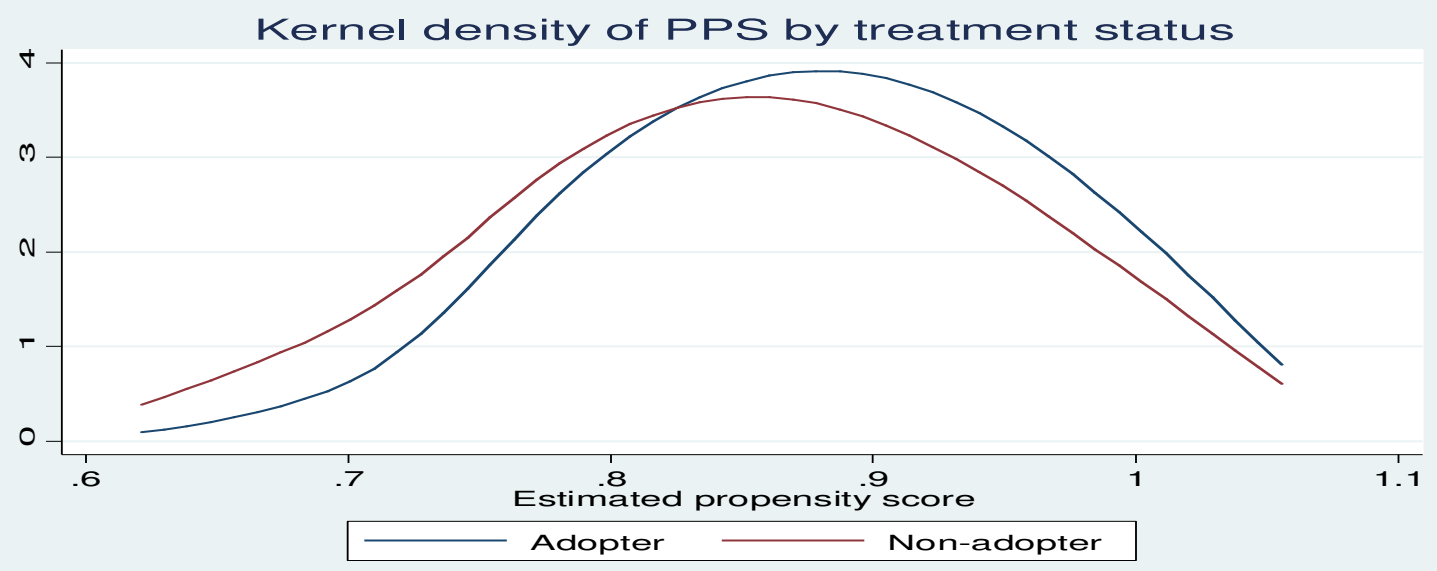

Figure 1(a): Distribution of propensity scores of adopters and non-adopters for Oromia region 


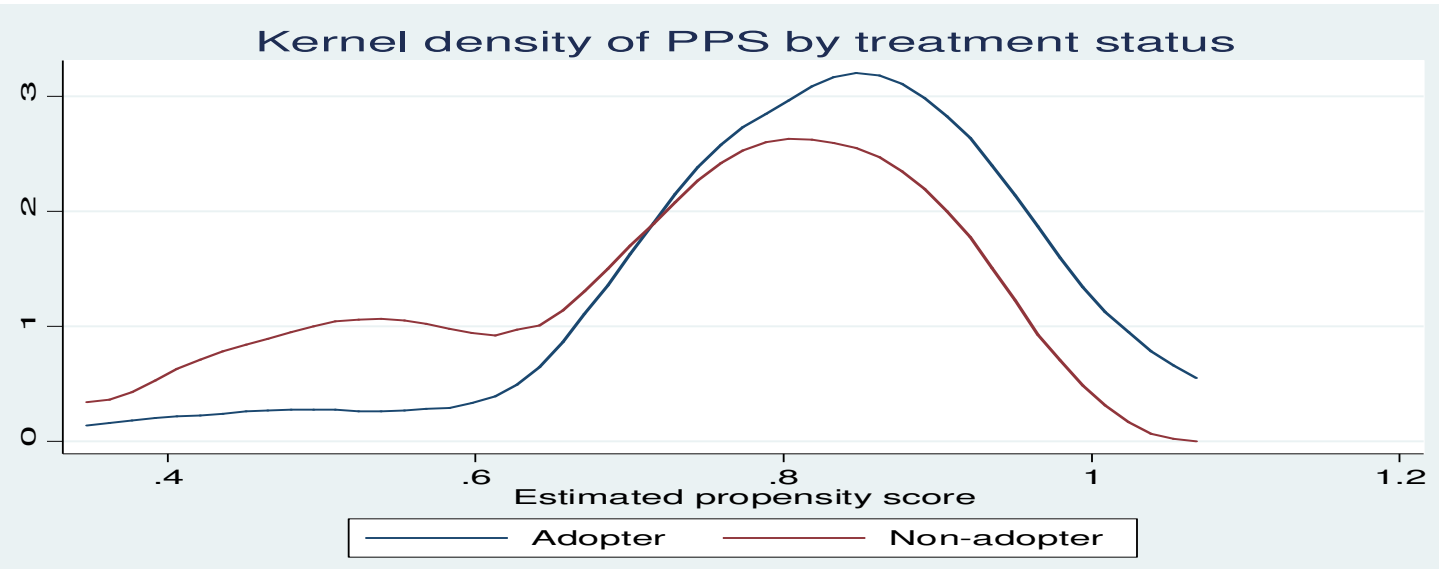

Figure 1(b): Distribution of propensity scores of adopters and non-adopters for Tigray region

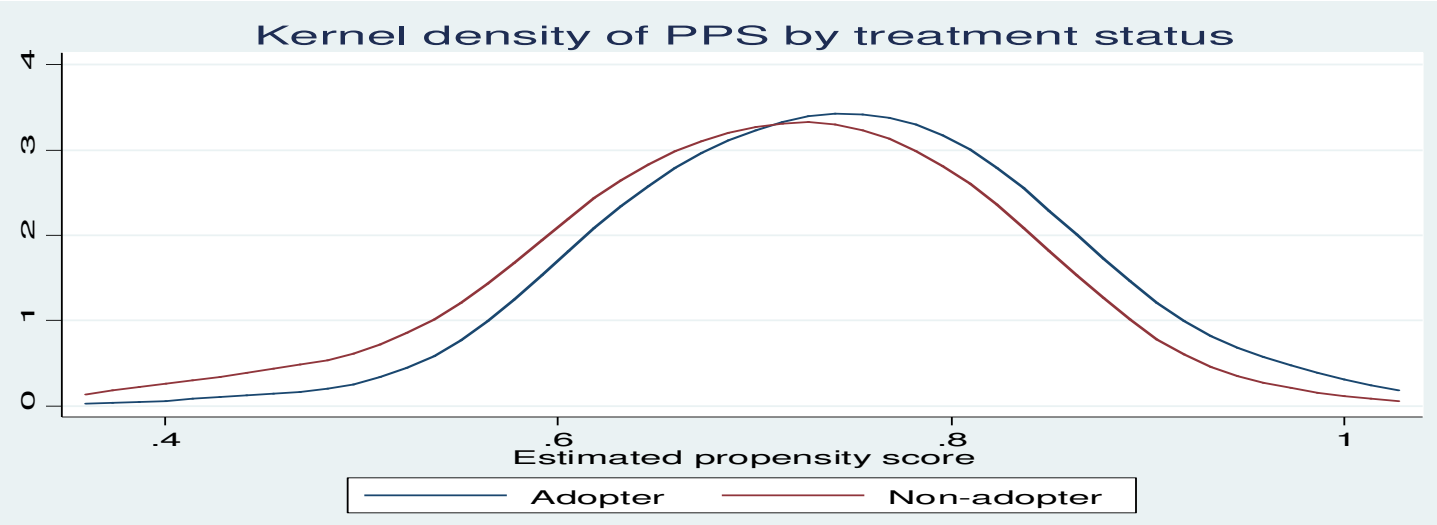

Figure 1(c): Distribution of propensity scores of adopters and non-adopters for Amhara region

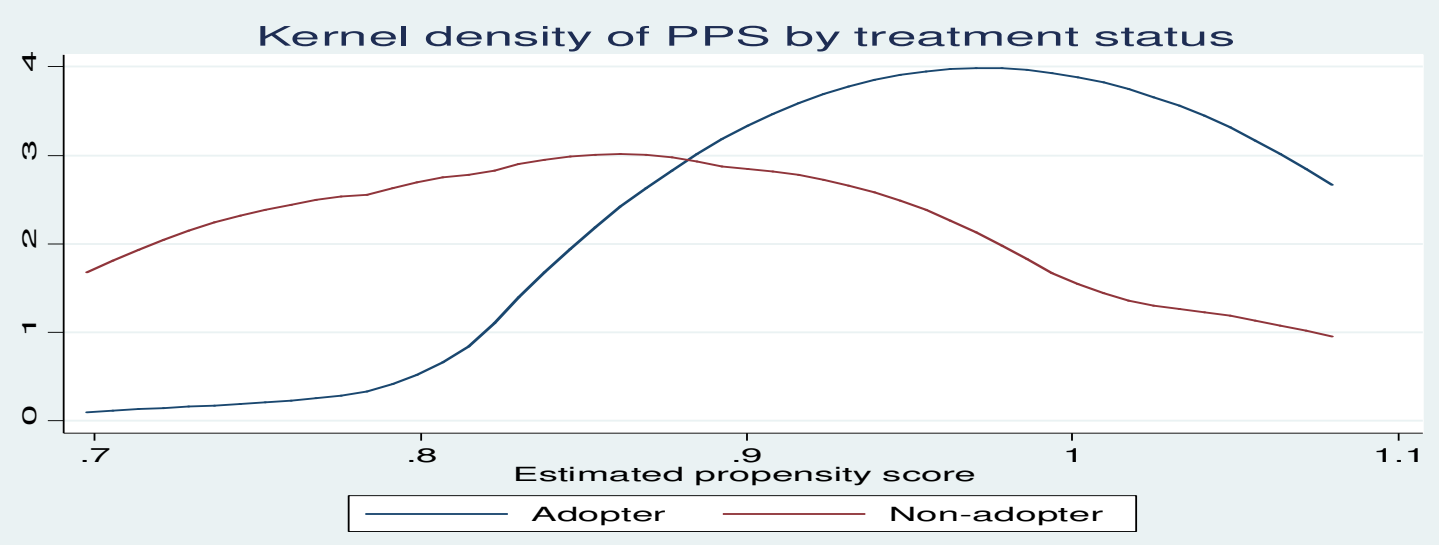

Figure 1(d): Distribution of propensity scores of adopters and non-adopters for SNNP region

\section{REFERENCES}

Abate T. , Shiferaw B., Menkir A. , Wegary D. , Kebede Y., Tesfaye K., Kassie M., Bogale G., Tadesse B. and Keno
T. (2015). Factors That Transformed Maize Productivity in Ethiopia. Food Sec. (2015) 7:965-981. 
Abegaz G. (2011). Cereal Productivity in Ethiopia: An Analysis Based on ERHS Data. Ethiopian Journal of Economics, Volume XX No. 2, October 2011.

Admassie A. and Ayele G, (2004). Adoption of Improved Technology in Ethiopia. Ethiopian Development Research Institute (EDRI), Research Report 3.

Olmos A. (2015). Propensity Scores: A Practical Introduction Using R. Journal of MultiDisciplinary Evaluation, Vol. 11, Issue 25, 2015.

Ayele G., Bekele M. and Zekeria S. (2006). Productivity and Efficiency of Agricultural Extension Package in Ethiopia. Ethiopian Development Research Institute (EDRI), Research Report 5.

Bor O. and Bayaner A. (2009). How Responsive is the Crop Yield to producer prices? A panel data approach for the case of Turkey. NEW MEDIT N. 4/2009.

Cochran, W. G. and D. B. Rubin. (1973). 'Controlling Bias in Observational Studies: A Review,' Sankhya, ser. A, 35:4, 417-446.

CSA. 2015. Major results of the 2007 GDP estimates. Central Statistical Agency (CSA), Addis Ababa, Ethiopia.

Elias A.,Nohmi M., Yasunobu K. \& Ishida A. (2013). Effect of Agricultural Extension Program on Smallholders' Farm Productivity: Evidence from Three Peasant Associations in the Highlands of Ethiopia. Journal of Agricultural Science, Vol. 5, No. 8, 2013.

Endale K. (2011). Fertilizer Consumption and Agricultural Productivity in Ethiopia. Ethiopian Development Research Institute (EDRI), Working Paper 003.

GebreEyesus A. (2015). A Study on Human Resource Management, Staff Turnover and Incentives in the National Agricultural Research System (NARS). Ethiopian Development Research Institute (EDRI), Research Report 27.

Gebre-Selassie A. and Bekele T. A Review of Ethiopian Agriculture: Roles, Policy and Small-scale Farming Systems. Global Growing Casebook.

Gebru A. (2006). The Determinants of Modern Agricultural Inputs Adoption and Their Productivity in Ethiopia (The Case of Amhara and Tigray Regions). A Thesis Submitted to the School of Graduate Studies of Addis Ababa University in Partial Fulfillment of the Requirements for the Degree of Master of Science in Economics (Economic Policy Analysis), July, 2006.

González V,, Ibarrarán P., Maffioli A. and Rozo S. (2009). The Impact of Technology Adoption on Agricultural Productivity: The Case of the Dominican Republic. InterAmerican Development Bank. Office of Evaluation and OversightWorking Paper: OVE/WP-05/09. September, 2009.
Heckman, J., H. Ichimura, and P. Todd. (1998). Matching as an Econometric Evaluation Estimator. The Review of Economic Studies 65(2): 261-294.

Kelemu K. (2017). Determinants of Farmers Access to Information about Improved Wheat Varieties: Case of Farmers in Major Wheat Growing Regions of Ethiopia. International Journal of Research in Agricultural Sciences, Volume 4, Issue 1, ISSN (Online): 2348 - 3997.

Ketema M., and Kassa B. (2016). Impact of Technology on Smallholder Wheat Production in Bale Highlands of Ethiopia: Application of Output Decomposition Model. Turkish Journal of Agriculture- Food Science and Technology, 4(6): 446-454.

Mann M. and Warner J. (2017). Ethiopian Wheat Yield and Yield Gap Estimation: A Spatially Explicit Small Area Integrated Data Approach. Field Crops Research 201 (2017) 60-74.

Matsumoto T. and Yamano T. (2010). The Impacts of Fertilizer Credit on Crop Production and Income in Ethiopia. National Graduate Institute for Policy Studies (GRIPS) Policy Research Center Discussion Paper 10-23, GRIPS, Tokyo.

MoFED. (2003). Rural Development Policy and Strategies. Economic Policy and Planning, Ministry of Finance and Economic Development, Addis Ababa.

Nigussie A., Kedir A., Adisu A., Belay G., Gebrie D. and Desalegn K. (2015). Bread Wheat Production in Small Scale Irrigation Users Agro-Pastoral Households in Ethiopia: Case of Afar and Oromia Regional State. Journal of Development and Agricultural Economics, Vol. 7(4), pp. 123-130.

Rosenbaum, P. and D. Rubin. (1983). The Central Role of the Propensity Score in Observational Studies for Causal Effects. Biometrika 70:1, 41-55.

Rosenbaum, P. and D. Rubin. (1985). Constructing a ControlGroup Using Multivariate MatchedSampling Methods that Incorporatethe Propensity Score. The AmericanStatistician Association, February1985, Vol. 39, No. 1.

Rubin, D. B. (1977). Assignment to Treatment Group on the Basis of a Covariate. Journal of Educational Statistics, 2, 1-26.

Taffesse A., Dorosh P. and Asrat S. (2012). Crop Production in Ethiopia: Regional Patterns and Trends. Summary of ESSP II Working Paper 16, "Crop Production in Ethiopia: Regional Patterns and Trends". ETHIOPIA STRATEGY SUPPORT PROGRAM (ESSP II) Research Note 11.

Tsusaka T. and Otsuka K. (2013). The Changes in The Effects of Temperature and Rainfall on Cereal Crop Yields in SubSaharan Africa: A Country Level Panel Data Study, 1989 to 2004. Environmental Economics, Volume 4, Issue 2, 2013. 